\title{
Below-ground competition drives the self-thinning process of Stipa purpurea populations in northern Tibet
}

\author{
Juntao Zhu, Lin Jiang, Yangjian Zhang, Yanbin Jiang, Jian Tao, Li Tian, Tao Zhang \& Yi Xi
}

\begin{abstract}
Keywords
Above-ground biomass; Below-ground biomass; Competition; Density dependence; Harsh environments; Population self-thinning; Precipitation gradient
\end{abstract}

\section{Abbreviation \\ $A M=$ alpine meadow; $A S=$ alpine steppe; $A D S$ $=$ alpine desert steppe; $\mathrm{MAP}=$ mean annual precipitation; MAT = mean annual temperature; $\mathrm{R} / \mathrm{S}=$ root/shoot ratios \\ Nomenclature \\ eFloras. Missouri Botanical Garden, St. Louis, MO \& Harvard University Herbaria, Cambridge, MA, 2008 (http://www.efloras.org) \\ Received 31 October 2013 \\ Accepted 08 May 2014 \\ Co-ordinating Editor: Francisco Pugnaire}

Zhang, Y. (corresponding author, zhangyj@igsnrr.ac.cn), Zhu, J. (zjt_1981@163.com), Jiang, Y. (violet840902@163.com), Tao, J. (taoj.10b@igsnrr.ac.cn), Tian, L. (tianli1123@163.com), Zhang, T. (zhangt.11b@igsnrr.ac.cn) \& Xi, Y. (xiy.12b@igsnrr.ac.cn): Lhasa Plateau Ecosystem Research Station, Key Laboratory of Ecosystem Network Observation and Modeling, Institute of Geographic Sciences and Natural Resources Research, Chinese Academy of Sciences, Beijing, 100101, China Jiang, L. (lin.jiang@biology.gatech.edu): School of Biology, Georgia Institute of Technology, Atlanta, GA, 30332, USA

Tao, J. (taoj.10b@igsnrr.ac.cn), Zhang, T. (zhangt.11b@igsnrr.ac.cn) \& Xi, Y.

(xiy.12b@igsnrr.ac.cn): University of Chinese Academy of Sciences, Beijing, 100049, China

\begin{abstract}
Questions: Above-ground, below-ground and individual mass-density relationships for perennial herbs were examined along a natural precipitation gradient in northern Tibet. We asked: (1) how do the self-thinning exponents respond to variation in precipitation; and (2) what mechanisms drive the observed population self-thinning?
\end{abstract}

Location: The alpine grassland of northern Tibet.

Methods: Forty-seven fenced sites along a precipitation gradient were established and surveyed in 2011 and 2012. Data (geographic coordinates, elevation, and vegetation information) were collected for Stipa purpurea populations at each site. Population self-thinning exponents were estimated using reduced major axis regression.

Results: The self-thinning exponents for below-ground $(-1.27,-0.47)$ and individual biomass $(-1.26,-0.46)$ increased with increasing mean annual precipitation, but those for above-ground biomass decreased with precipitation $(0.18,-0.25)$. Soil resources (moisture and nutrients) are a more important constraining factor for below-ground components than light is for above-ground components. Root competition for below-ground resources dominated in S. purpurea population self-thinning. The driving force of density regulation changed from above-ground competition to below-ground competition with increased drought stress. Our results indicate that an increased root/shoot ratio was linked to enhanced below-ground competition and weakened above-ground competition. Our study further confirmed the hypothesis that plant populations in different environments exhibit different biomass allocation patterns, which, in turn, leads to different biomass-density relationships.

Conclusions: Our study revealed the mechanisms of population self-thinning for perennial herbs in the extreme environment of northern Tibet, where below-ground processes play a critical role in regulating population self-thinning. Our study also advances understanding of the interactions between aboveand below-ground processes, providing baseline knowledge useful for local grassland management.

\section{Introduction}

As a process of density-dependent mortality in even-aged communities (Reynolds \& Ford 2005), population selfthinning is commonly observed in natural and artificial plant populations (Han \& Fang 2008). To describe this process, Yoda et al. (1963) put forward an empirical equation stated to hold for all plant species:

$$
M=k N^{\gamma}
$$

where $M$ is mean plant biomass; $N$ is population density; $k$ and $\gamma$ are, respectively, the intercept and exponent relating 
biomass to population density (Osawa \& Kurachi 2004). Considerable debate exists on the value of the self-thinning exponent $(\gamma)$. The ' $-3 / 2$ ' law and ' $-4 / 3$ ' laws, proposed by Yoda et al. (1963) and Enquist et al. (1998), respectively, are considered by some as general rules in plant ecology. However, other ecologists consider these two laws as unsubstantiated hypotheses that lack theoretical and empirical justification (Lonsdale 1990; Kozlowski \& Konarzewski 2004; Deng et al. 2006; Dai et al. 2009). It was suggested that $\gamma$ could vary with environmental conditions, such as light availability (Hiroi \& Monsi 1966; Lonsdale \& Watkinson 1982), soil fertility (Morris 2002, 2003), water availability (Deng et al. 2006; Dai et al. 2009) or salt concentration (Chu et al. 2008). It is also notable that studies of mass-density relationships have largely focused on woody plants, with little attention given to herbaceous species.

In most studies of population self-thinning, $M$ generally includes only above-ground biomass (Yoda et al. 1963; Enquist et al. 1998), reflecting methodological difficulties in the measurement of below-ground biomass (Ogawa 2005; Mokany et al. 2006). As a result, we still know little about the relationship between below-ground biomass and self-thinning (Zhang et al. 2011). A number of studies, conducted on herbs (Morris \& Myerscough 1991; Morris 1999, 2002, 2003) tree seedlings (Ogawa 2005) and desert shrub communities (Deng et al. 2006; Bai et al. 2010), have proposed that below-ground competition may be a major factor in driving density-dependent mortality and hence self-thinning. However, despite progress so far, there is still a lack of comparison among above-ground, below-ground and individual self-thinning processes in plants, especially in herbaceous plants.

The optimal partitioning theory suggests that low soil nutrient availability and low light supply would result in increased allocation to roots and leaves, respectively (Thornley 1972; Bloom et al. 1985), and that there might be a relationship between self-thinning exponents and biomass allocation (Bai et al. 2010). Consistent with these suggestions, it has been reported that above-ground competition for light drives the process of self-thinning for forest communities in the absence of drought stress (Hiroi $\&$ Monsiet 1966; Xue \& Hagihara 1999), and that root competition drives the process of density-dependent mortality for desert shrubs in arid regions (Deng et al. 2006). Moreover, the extent of environmental stress is known to affect the nature of species interactions, such that competitive interactions that tend to dominate in benign environments could turn into facilitative interactions in stressed habitats (stress gradient hypothesis; Bertness \& Callaway 1994; Callaway et al. 2002). The balance between facilitation and competition might thus influence plant biomass-density relationships. Few studies, however, have investigated how facilitative and competitive interactions combine to influence population self-thinning along environmental gradients (but see Chu et al. 2008).

The Northern Tibetan Plateau vegetation ecosystems exist under extreme environmental conditions, including intense radiation, strong winds, low temperatures, low soil nutrients and drought stress (Li et al. 2011; Yu et al. 2012). There are three main natural vegetation types: alpine meadow (dominated by Kobresia pygmaea), alpine steppe (dominated by Stipa purpurea) and alpine desert steppe (dominated by Stipa subsessiliflora) (Li et al. 2011), and all plants are perennial herbs. S. purpurea alpine steppe is one of the most important grassland types in northern Tibet, providing the main food source for local livestock (Hu et al. 2012). A natural precipitation gradient exists from east to west in northern Tibet (Wu et al. 2012), accompanied by relatively small variations in mean annual temperature and soil properties across the gradient (Cao \& Wang 2012), providing a rare opportunity to examine the mass-density relationship for perennial herbs along a precipitation gradient under extreme environments. We hypothesize that, (1) self-thinning exponents will vary across the rainfall gradient, and (2) the variation in biomass allocation mode will change biomass-density relationships. We further asked what mechanisms drive the observed population self-thinning.

\section{Methods}

\section{Study area}

The Northern Tibetan Plateau (locally named Changtang) is in the hinterland of the Qinghai-Tibet Plateau (Cincotta et al. 1991; 29; ${ }^{\circ} 53^{\prime}-36^{\circ} 32^{\prime} \mathrm{N}, 78^{\circ} 41^{\prime}-92^{\circ} 16^{\prime} \mathrm{E}$ ), covering an area of $597000 \mathrm{~km}^{2}$ (Fig. 1). We set up a west-east alpine grassland transect (the Northern Tibetan Plateau Alpine Grassland Transect, NTPAGT) in May 2009 (Wu et al. 2012). The NTPAGT covers $79.71-92.03^{\circ} \mathrm{E}$ and $30.50-33.45^{\circ} \mathrm{N}$, and is ca. $1200-\mathrm{km}$ long and $400-\mathrm{km}$ wide (Li et al. 2011). The NTPAGT traverses three main natural vegetation types: alpine meadow (AM, dominated by K. pygmaea), alpine steppe (AS, dominated by S. purpurea) and alpine desert steppe (ADS, dominated by $S$. subsessiliflora) (Li et al. 2011). Alpine steppe, dominated by S. purpurea (growth period May to September, about $120 \mathrm{~d}$ ), is the most widely distributed vegetation type on the Northern Tibetan Plateau (Chinese Academy of Sciences, Intergrative Expedition Team to Qinghai-Tibet Plateau 1988). The mean annual precipitation (MAP) for alpine steppe varies from 120 to $500 \mathrm{~mm}$, and mean annual temperature (MAT) ranges from -0.89 to $-0.32{ }^{\circ} \mathrm{C}$ (Table 1$)$. The elevation of the sample sites was from 4374 to $4953 \mathrm{~m}$. According to distribution area of $S$. purpurea populations, we divided mean annual precipitation (120-500 mm) into 


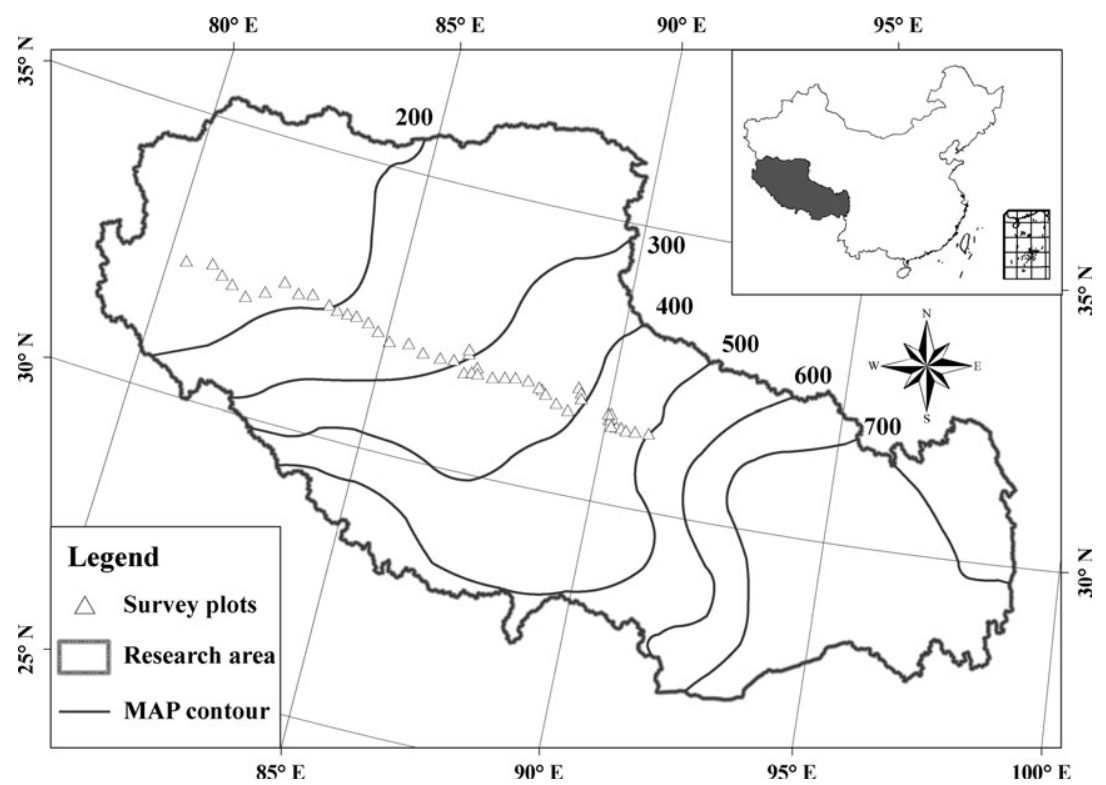

Fig. 1. Distribution of the 47 study sites along the Northern Tibetan Plateau Alpine Grassland Transect.

Table 1. The geographic and climatic conditions and characteristics of soil and natural vegetation along a precipitation gradient in northern Tibet. Mean \pm SD

\begin{tabular}{lccccc}
\hline Parameters & \multicolumn{2}{l}{ Precipitation Gradient } & & & \\
\cline { 2 - 6 } & $120-180 \mathrm{~mm}$ & $180-260 \mathrm{~mm}$ & $280-360 \mathrm{~mm}$ & $360-440 \mathrm{~mm}$ & $440-500 \mathrm{~mm}$ \\
\hline Altitude $(\mathrm{m})$ & $4406-4814$ & $4374-4877$ & $4494-4953$ & $4533-4666$ & $4548-4803$ \\
MAT $\left({ }^{\circ} \mathrm{C}\right)$ & -0.89 & -0.59 & -0.32 & -0.41 & -0.45 \\
Soil Moisture Content (\%) & $2.36-9.94$ & $3.80-14.38$ & $7.38-21.42$ & $10.41-23.52$ & $10.73-26.28$ \\
Vegetation Cover (\%) & $28 \pm 2.15$ & $35 \pm 3.28$ & $38 \pm 2.84$ & $43 \pm 3.55$ & $48 \pm 4.86$ \\
Mean Root/Shoot Ratio & $23 \pm 5.35$ & $20 \pm 5.54$ & $15 \pm 3.48$ & $11 \pm 2.16$ & $8 \pm 2.25$ \\
\hline
\end{tabular}

five levels: 120-180, 180-260, 280-360, 360-440 and 440-500 mm.

\section{Data collection}

Field surveys were conducted in late July to early August 2011 and 2012. The sampled vegetation is composed mainly of $S$. purpurea with low species diversity; other less common, but frequently observed species include Poa annua, Koresia macrantha, Carex moorcroftii, Festuca ovina, Oxytropis microphylla, Potentilla bifurca, Leontopodium nanum and Saussurea stella. Forty-seven fenced sites along a precipitation gradient were established and surveyed (Fig. 1). We recorded geographic coordinates, elevation, soil moisture content (TDR300, Spectrum, California, CA, USA) and vegetation type for each site. Five $1 \times 1-\mathrm{m}$ quadrats were laid out randomly within each $100 \times 100-\mathrm{m}$ site and all vascular plant species were recorded. The number of species, number of individual plants (genets and ramets), canopy cover, abovebiomass and below-ground biomass were measured in each quadrat. All above-ground biomass was clipped to ground level. The sites were surveyed in 2011 and 2012, and te data were averaged over the $2 \mathrm{yr}$. The below-ground biomass was sampled by randomly taking a $7-\mathrm{cm}$ diameter soil core to $50-\mathrm{cm}$ depth within each of the five quadrats (depth intervals: 0-5, 5-10, 10-20, 20-30, 30-50 cm). Six soil samples were collected from 0 to $5 \mathrm{~cm}$ and from 5 to $10 \mathrm{~cm}$; three soil samples were collected from 10 to $20 \mathrm{~cm}$ and from 20 to $30 \mathrm{~cm}$; two soil samples were collected from 30 to $50 \mathrm{~cm}$. Soil was rinsed from roots under running water over a l-mm screen. Above- and below-ground samples were weighed after removing dead parts and oven-dried at $65{ }^{\circ} \mathrm{C}$ for $72 \mathrm{~h}$ to a constant weight. In Tibetan grasslands, about $90 \%$ of total root biomass occurs in the top $30 \mathrm{~cm}$ of soil (Yang et al. 2009). We calculated the below-ground biomass across the five depth intervals. The above-, below-ground and total biomass at each site was averaged across the five quadrats. Mean above-, below-ground and total biomass for each individual plant was calculated by dividing the population 
biomass of its species by its population size. We then calculated root/shoot $(R / S)$ ratios for all sampling sites.

Daily air temperatures and rainfall throughout each year from 1982 to 2011 were obtained from the National Meteorological Information Centre of China Meteorological Administration. Mean annual precipitation and temperature for each site were extrapolated using a geographic information system-based multiple regression method (Bai et al. 2007) in ArcGIS 9.2 (ERSI, Redlands, CA, US).

\section{Data analysis}

As observed vegetation cover is only $28-48 \%$ over the rainfall gradient, the plant canopy is not closed at all sites, thus plant biomass may be at a maximum for this environment (Fowler 1986). Specifically, plant stands may maintain a relatively steady structure and energy balance under limited resources during the thinning process. The $\log M-\log N$ regression lines may therefore reflect the self-thinning process (Deng et al. 2006). The allometric exponents or slopes $(\gamma)$ and the intercept $(k)$ in the allometric equation $\left(M=k N^{\gamma}\right)$ were estimated using reduced major axis (RMA) regression of the log-transformed data. In analysing the exponents, statistical significances were tested based on 95\% CIs. The additional calculated variables were: $N=n / s$, $B=b / s, M=B / N$, where $N, B, M, n, b$ and $s$ represent population density, above-/below-ground biomass per area, mean above-/below-ground biomass, number of individuals, total above-/below-ground biomass and sample area, respectively. The $R / S$ ratios for each of the five precipitation levels were used as independent variables in linear regression models, and with above-ground, below-ground $M-N$ allometric exponents $(\gamma)$ as dependent variables. All statistical analyses were conducted in SPSS (v 13.0; SPSS Inc., Chicago, IL, US).

\section{Results}

The slopes of self-thinning lines for above-ground plant parts became steeper with increasing mean annual precipitation (MAP; Fig. 2). When MAP was 360-500 mm, the above-ground allometric exponents were negative; there was no significant relationship between above-ground biomass and density (i.e. zero slope) when MAP was 180-360 mm $(P>0.05)$; when MAP was $<180 \mathrm{~mm}$, the exponent for above-ground biomass was significantly positive (Table 2, Fig. 2), i.e. above-ground biomass significantly increased with increasing population density.

The allometric exponents for below-ground and individual biomass, however, showed an opposite trend with MAP. Specifically, both slopes of self-thinning lines became flatter as MAP increased (Figs 3 and 4). Note that only when rainfall was $120-180 \mathrm{~mm}$ were the allometric exponents for below-ground and individual biomass-density relationships close to $-4 / 3$; their $95 \%$ CIs $(-1.57$,
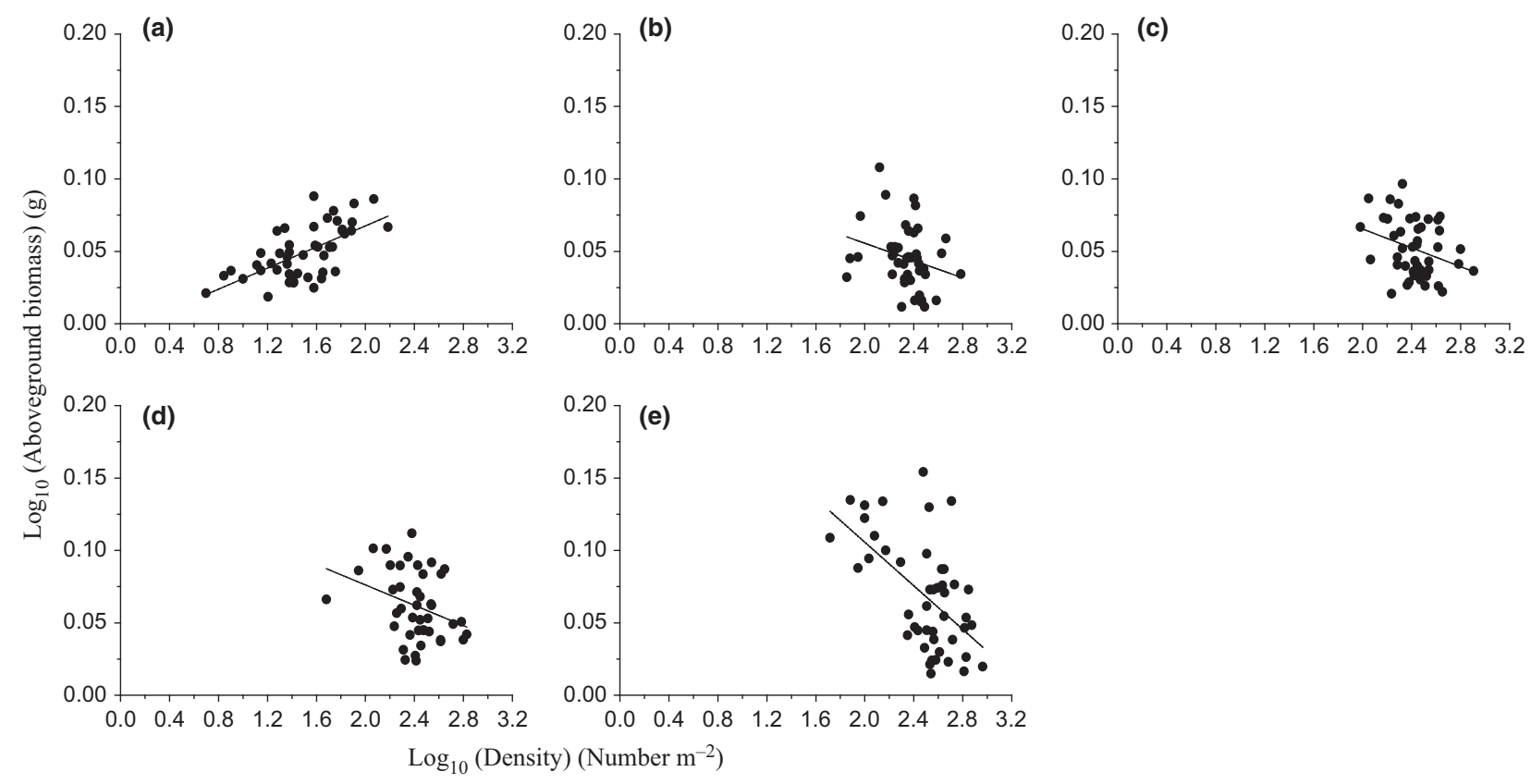

Fig. 2. $M-N$ relationships between above-ground biomass and plant density of Stipa purpurea populations along a natural precipitation gradient in northern Tibet. (a) 120-180 mm; (b) 180-260 mm; (c) 280-360 mm; (d) 360-440 mm; (e) 440-500 mm. 
Table 2. Slopes and intercepts of linear relationships between mean above-ground, below-ground and individual biomass and population density along a precipitation gradient as estimated from the reduced major axis method.

\begin{tabular}{|c|c|c|c|c|c|c|c|c|}
\hline Regression M:D & $\mathrm{MAP}(\mathrm{mm})$ & Slope & $95 \% \mathrm{Cl}$ & Intercept & $95 \% \mathrm{Cl}$ & $R^{2}$ & $n$ & $P$-value \\
\hline \multirow[t]{5}{*}{ Above-Ground Biomass } & $440-500$ & -0.25 & $-0.31,-0.17$ & 0.39 & $0.29,0.48$ & 0.13 & 55 & $<0.001$ \\
\hline & $360-440$ & -0.17 & $-0.24,-0.11$ & 0.37 & $0.26,0.44$ & 0.22 & 45 & $<0.001$ \\
\hline & $280-360$ & -0.15 & $-0.20,-0.12$ & 0.34 & $0.26,0.37$ & 0.10 & 50 & $>0.05$ \\
\hline & $180-260$ & -0.10 & $-0.15,-0.07$ & 0.32 & 0.25 .0 .38 & 0.08 & 45 & $>0.05$ \\
\hline & $120-180$ & 0.18 & $0.09,0.21$ & -0.12 & $-0.18,-0.07$ & 0.15 & 40 & $<0.05$ \\
\hline \multirow[t]{5}{*}{ Below-Ground Biomass } & $440-500$ & -0.47 & $-0.60,-0.35$ & 1.49 & $1.18,1.80$ & 0.21 & 55 & $<0.001$ \\
\hline & $360-440$ & -0.67 & $-0.83,-0.51$ & 2.00 & $1.62,2.38$ & 0.39 & 45 & $<0.001$ \\
\hline & $280-360$ & -0.83 & $-1.03,-0.64$ & 2.36 & $2.01,2.71$ & 0.39 & 50 & $<0.001$ \\
\hline & $180-260$ & -1.20 & $-1.53,-0.87$ & 2.75 & $2.30,3.24$ & 0.17 & 45 & $<0.001$ \\
\hline & $120-180$ & -1.27 & $-1.57,-0.96$ & 2.83 & $2.36,3.30$ & 0.35 & 40 & $<0.001$ \\
\hline \multirow[t]{5}{*}{ Individual Biomass } & $440-500$ & -0.46 & $-0.58,-0.35$ & 1.47 & $1.17,1.78$ & 0.21 & 55 & $<0.001$ \\
\hline & $360-440$ & -0.65 & $-0.82,-0.50$ & 2.00 & $1.62,2.38$ & 0.40 & 45 & $<0.001$ \\
\hline & $280-360$ & -0.83 & $-1.03,-0.64$ & 2.36 & $2.01,2.71$ & 0.39 & 50 & $<0.001$ \\
\hline & $180-260$ & -1.18 & $-1.51,-0.85$ & 2.72 & $2.28,3.23$ & 0.16 & 45 & $<0.001$ \\
\hline & $120-180$ & -1.26 & $-1.55,-0.95$ & 2.82 & $2.35,3.30$ & 0.35 & 40 & $<0.001$ \\
\hline
\end{tabular}
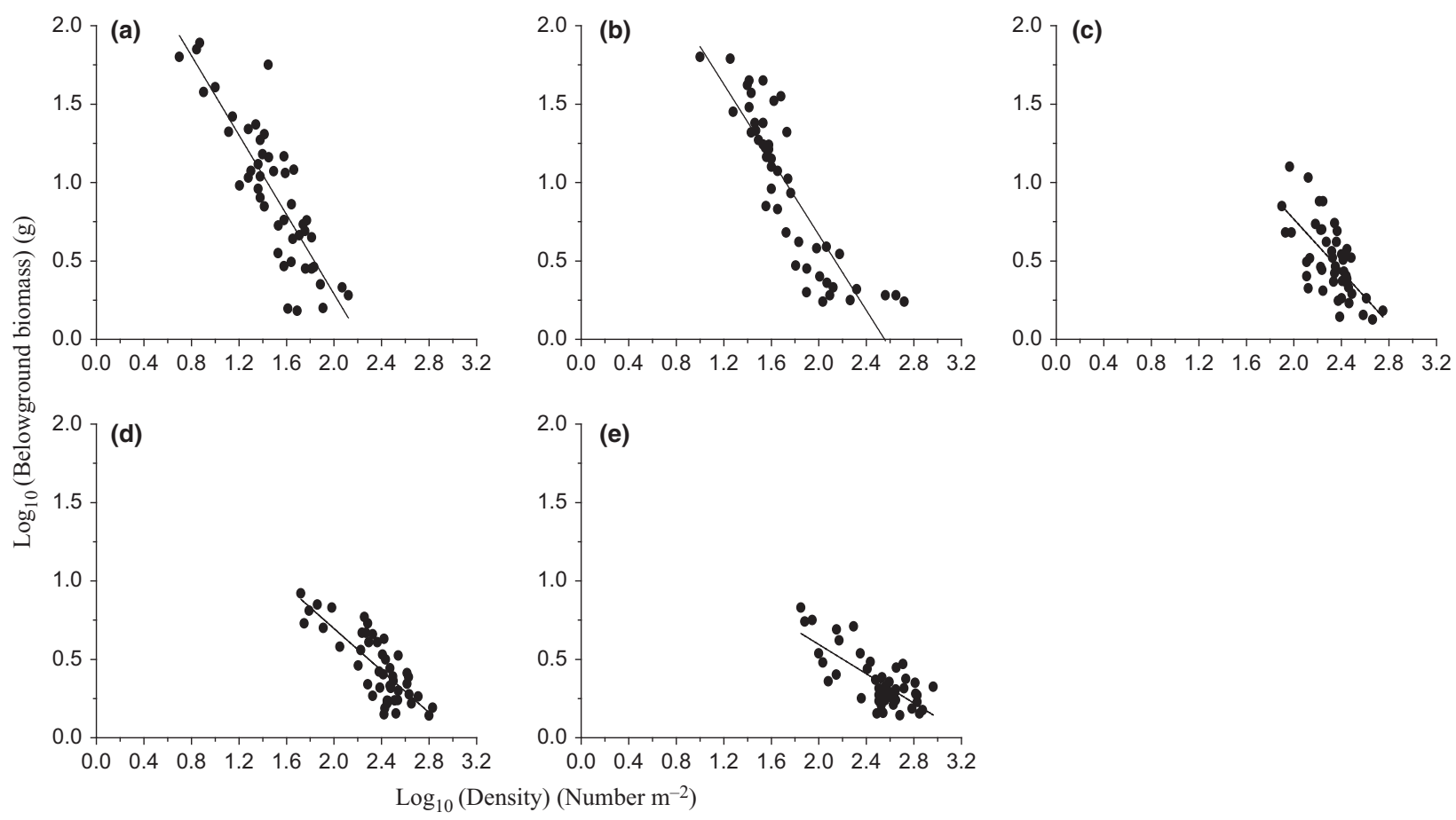

Fig. 3. $M-N$ relationships between below-ground biomass and plant density of Stipa purpurea populations along a natural precipitation gradient in northern Tibet. (a) 120-180 mm; (b) 180-260 mm; (c) 280-360 mm; (d) 360-440 mm; (e) 440-500 mm.

-0.96 and $-1.55,-0.95$, respectively), however, included both $-4 / 3$ and $-3 / 2$ (Table 2 ).

Mean vegetation cover was $28-48 \%$ across all sites, and increased with increasing MAP (Table 1). This variable exhibited a negative relationship with the $R / S$ ratio, which decreased with increasing MAP (Table 1). Across the five precipitation regions, the allometric exponents for the above-ground biomass-density relationship increased with increasing $R / S\left(R^{2}=0.69, P<0.001\right.$; Fig. 5), while for the below-ground biomass-density relationship it decreased with $R / S\left(R^{2}=0.96, P<0.001\right.$; Fig. 5).

\section{Discussion}

Responses of above- and below-ground exponents to precipitation variations

Studies on the responses of self-thinning exponents to precipitation variations are more common in arid and 


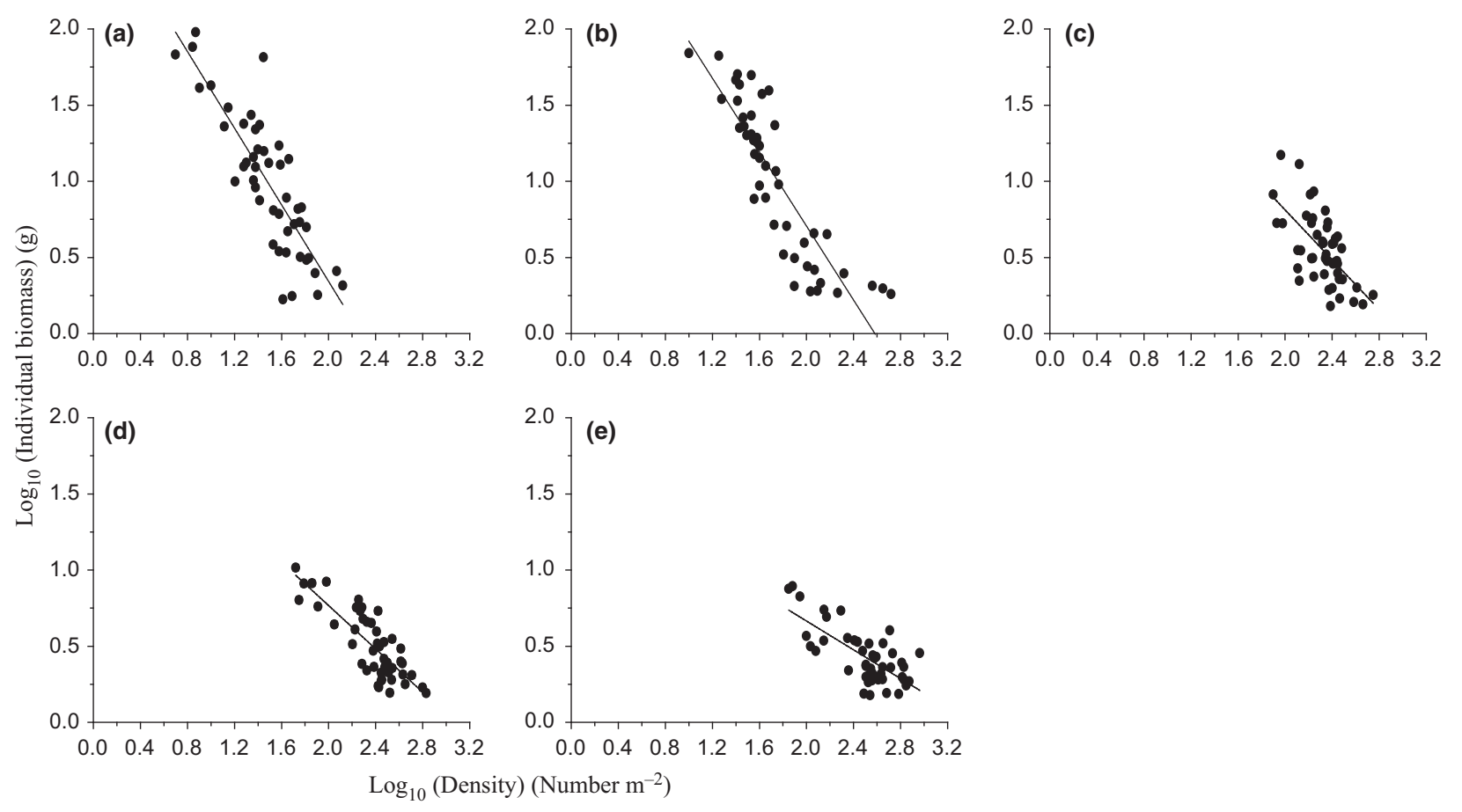

Fig. 4. $M-N$ relationships between individual biomass and plant density of Stipa purpurea populations along a natural precipitation gradient in northern Tibet. (a) 120-180 mm; (b) 180-260 mm; (c) 280-360 mm; (d) 360-440 mm; (e) 440-500 mm.

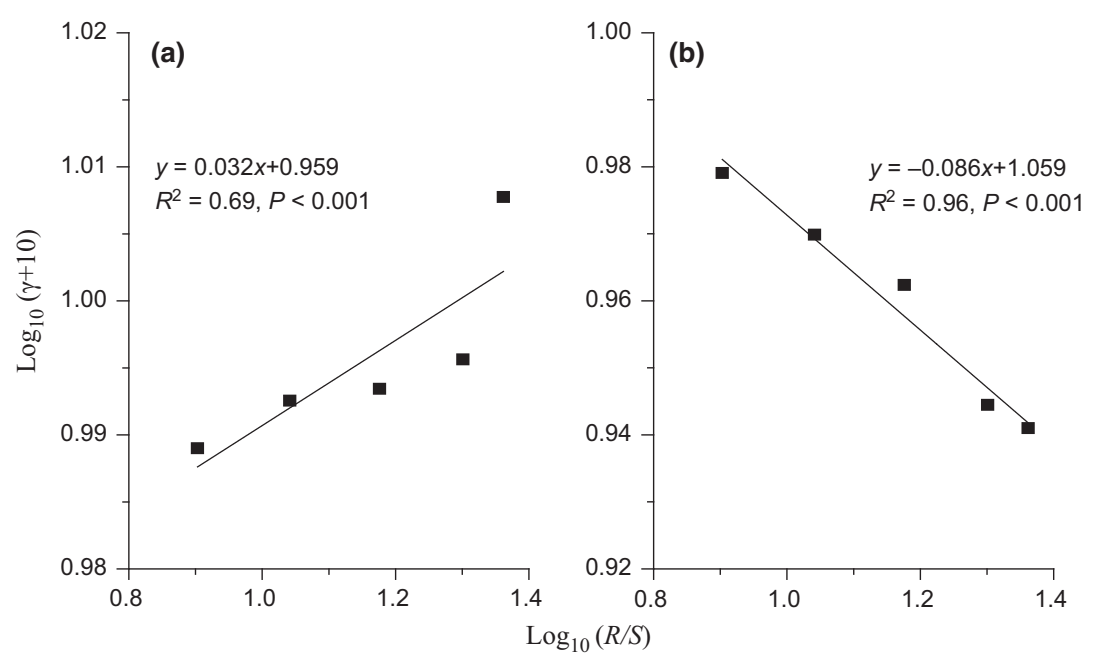

Fig. 5. The relationships between root/shoot ratios $(R / S)$ and above-ground (a) and below-ground (b) $M-N$ allometric exponents $(\gamma)$ for the five precipitation levels along the precipitation gradient.

semi-arid regions (Deng et al. 2006; Dai et al. 2009; Bai et al. 2010). In the present study, the largest difference in mean annual temperature (MAT) is less than $1{ }^{\circ} \mathrm{C}$, which is trivial compared to the wide range of the precipitation gradient. We consequently focused on the effects of the precipitation gradient on the exponents. The slopes of self-thinning lines for below-ground parts became flatter as MAP increased, while the opposite trend was observed for above-ground parts. Several other studies in arid regions also reported that slopes of self-thinning lines for above-ground plant parts become steeper as MAP increases (Deng et al. 2006; Dai et al. 2009). 
One interesting result with regard to the above-ground $M-N$ allometric exponent is a declining trend with increasing MAP. Specifically, it was significantly positive for the lowest precipitation, not different from zero for intermediate precipitation and significantly negative for the highest precipitation; i.e., in the extreme environment of northern Tibet, population self-thinning occurred only when rainfall was relatively abundant, and above-ground biomass actually increased with population density under drought stress. These results could potentially be explained through the stress gradient hypothesis (Bertness \& Callaway 1994; Callaway 2007), which emphasizes the relative importance of competition and facilitation along environmental stress gradients. Applying this hypothesis to our study system, we suggest that competition may be important and drive self-thinning in regions that receive abundant rainfall, and that facilitation may be important in regions with relatively little rainfall. Facilitation may occur in this extreme environment, as observed for (non-thinning) populations (Chu et al. 2008). Plants with higher population densities can improve local temperature, slow wind and create a relatively stable soil environment, such that plants provide mutual support to withstand adverse conditions (Callaway 2007). An alternative explanation, if the populations are truly self-thinning, is that root competition is so severe that surviving plants show negative growth responses in above-ground biomass (Morris 1999).

\section{Mechanisms of population self-thinning}

Newman (1973) proposed that below-ground competition becomes more important with increasing abiotic stress in plant populations. Bai et al. (2010) also proposed that the driving forces of density regulation might shift from canopy to root competition under environmental stress. The Northern Tibetan Plateau is a system under extreme abiotic environmental conditions. The slopes of self-thinning lines for above-ground parts become flatter under drought stress, while for below-ground parts lines become stepper with drought stress. Hence, the intensity of density-dependent regulation of above- and below-ground biomass changed during drought stress: it decreased with stress for above-ground biomass and increased with stress for below-ground biomass (Li \& Zhou 2011).

The optimal partitioning theory suggests that lower nutrient supply increases allocation to roots, and lower light supply increases allocation to leaves (Bloom et al. 1985). Therefore, when water supply is limited, accompanied by lower nutrient availability, plants preferentially allocate more biomass to below-ground parts, and the $R / S$ ratio increases (Brown $\&$ Lugo 1982). Our study corroborates these predictions. Dai et al. (2009) proposed that the slopes of self-thinning lines for above-ground parts become flatter with declining MAP, and this might be interpreted in decreasing above-ground biomass with increasing drought stress, as plants allocate more biomass to below-ground parts. In the present study, the $R /$ $S$ ratio was positively correlated with the self-thinning exponents for above-ground biomass and negatively with below-ground biomass (Fig. 5). An increased $R / S$ ratio with increasing drought stress indicates that plants allocated more biomass to below-ground parts as they grew larger to maximize uptake of water and nutrient resources (Bloom et al. 1985). The resultant higher below-ground competition under increased drought stress presumably led to smaller exponents for belowground biomass; the resultant weaker above-ground competition under increased drought stress presumably led to larger exponents for above-ground biomass. Our results further confirmed the hypothesis that plant populations in different environments exhibit different biomass allocation patterns, which, in turn, lead to different biomass-density relationships (Bai et al. 2010).

\section{Below-ground competition regulates population self- thinning}

Above- and below-ground and individual biomass were influenced by density regulation $(\gamma<0)$, the result of both intraspecific and interspecific competition (Ogawa 2005). As the $\gamma$-value reflects the magnitude of density dependence (the smaller the value, the higher the intensity of density dependence; Li \& Zhou 2011), we conclude that the effect of density-dependent regulation on belowground biomass was greater than that on above-ground biomass. In this study area, solar radiation is 5000$8000 \mathrm{MJ} \cdot \mathrm{m}^{-1} \cdot \mathrm{yr}^{-1}$, mean soil moisture content is $2.36-26.28 \%(0-20 \mathrm{~cm})$ and mean $N$ content is $0.05-$ $0.12 \%(0-20 \mathrm{~cm}$; our data). We thus inferred that light limitation for above-ground parts was not important, while soil moisture and nutrients were limited for belowground plant parts. Consequently, root competition for below-ground resources dominated $S$. purpurea population self-thinning. Other recent studies also recognized that root competition can play an important role in regulating plant populations (Morris 1999, 2002, 2003; Deng et al. 2006; Li et al. 2012). Our results identified the importance of below-ground competition on plant population regulation in environmentally stressed regions.

\section{Acknowledgements}

This research is supported by the 973 Program (2013CB956302) of the Ministry of Science and Technology of China; One Hundred Talent Plan, Chinese Academy of Sciences; the Ministry of Science and Technology of the 
People's Republic of China (MOST) 973 Program (2010CB950603); National Youth Natural Science Foundation of China (41 101056); and West Light Foundation of The Chinese Academy of Sciences. The authors are also grateful to Professor Yan Li for his valuable comments.

\section{References}

Bai, Y.F., Wu, J.G., Pan, Q.M., Huang, J.H., Wang, Q.B., Li, F.S., Buyantuyev, A.A. \& Han, X.G. 2007. Positive linear relationship between productivity and diversity: evidence from the Eurasian steppe. Journal of Applied Ecology 44: 1023-1034.

Bai, Y.Y., Zhang, W.P. \& Jia, X. 2010. Variation in root:shoot ratios induced the differences between above- and belowground mass-density relationships along an aridity gradient. Acta Oecologica 36: 393-395.

Bertness, M.D. \& Callaway, R. 1994. Positive interactions in communities. Trends in Ecology $\theta$ Evolution 9: 191-193.

Bloom, A.J., Chapin, F.S. \& Mooney, H.A. 1985. Resource limitation in plants - an economic analogy. Annual Review of Ecology and Systematics 16: 363-392.

Brown, S. \& Lugo, A.E. 1982. The storage and production of organic matter in tropical forests and their role in the global carbon cycle. Biotropica 14: 161-187.

Callaway, R.M. 2007. Positive Interactions and Interdependence in Plant Communities. Springer, Dordrecht.

Callaway, R.M., Brooker, R.W., Choler, P., Kikvidze, Z., Lortie, C.J., Michalet, R., Paolini, L., Pugnaire, F.I., Newingham, B., (...) \& Cook, B.J. 2002. Positive interactions among alpine plants increase with stress. Nature 417: 844-848.

Cao, Y.Z. \& Wang, X.D. 2012. Spatial distribution of soil organic carbon and influencing factors in the alpine steppe of northern Tibet. Ecology and Environmental Sciences 21: 213-219.

Chinese Academy of Sciences, Intergrative Expedition Team to Qinghai-Tibet Plateau. 1988. The vegetation of Xizang (Tibet). Science Press, Beijing, CN. [In Chinese.]

Chu, C.J., Maestre, F.T., Xiao, S., Weiner, J., Wang, Y.S., Duan, Z.H. \& Wang, G. 2008. Balance between facilitation and resource competition determines biomass-density relationships in plant populations. Ecology Letters 11: 1-9.

Cincotta, R.P., Vansoest, P.J., Robertson, J.B., Beall, C.M. \& Goldstein, M.C. 1991. Foraging ecology of livestock on the Tibetan Changtang: a comparison of three adjacent grazing areas. Arctic and Alpine Research 23: 149-161.

Dai, X.F., Jia, X., Zhang, W.P., Bai, Y.Y., Zhang, J.Y., Wang, Y. \& Wang, G.X. 2009. Plant height-crown radius and canopy coverage-density relationships determine above-ground biomass-density relationship in stressful environments. Biology Letters 5: 571-573.

Deng, J.M., Wang, G.X., Morris, E.C., Wei, X.P., Li, D.X., Chen, B.M., Zhao, C.M., Liu, J. \& Wang, Y. 2006. Plant mass-density relationship along a moisture gradient in north-west China. Journal of Ecology 94: 953-958.

Enquist, B.J., Brown, J.H. \& West, G.B. 1998. Allometric scaling of plant energetics and population density. Nature 395: 163-165.
Fowler, N. 1986. The role of competition in plant communities in arid and semiarid regions. Annual Review of Ecology and Systematics 17: 89-110.

Han, W.X. \& Fang, J.Y. 2008. Self-thinning law in plant populations: $-3 / 2$ vs $-4 / 3$. Acta Scientiarum Naturalium Universitatics Pekinensis 44: 661-668.

Hiroi, T. \& Monsi, M. 1966. Dry-matter economy of Helianthus annuus communities grown at varying densities and light intensities. Journal of the Faculty of Science University of Tokyo 9: 241-285.

Hu, M.Y., Zhang, L., Luo, T.X. \& Shen, W. 2012. Variations in leaf functional traits of Stipa purpurea along a rainfall gradient in Xizang, China. Chinese Journal of Plant Ecology 36: 136143. [In Chinese.]

Kozlowski, J. \& Konarzewski, M. 2004. Is West, Brown and Enquist's model of allometric scaling mathematically correct and biologically relevant? Functional Ecology 18: 283-289.

Li, L. \& Zhou, D.W. 2011. Density-dependent regulation of aboveand below-ground modules in Allium cepa var. proliferum populations. Chinese Journal of Plant Ecology 35: 284-293. [In Chinese.]

Li, X.J., Zhang, X.Z., Wu, J.S., Shen, Z.X., Zhang, Y.J., Xu, X.L., Fan, Y.Z., Zhao, Y.P. \& Yan, W. 2011 . Root biomass distribution in alpine ecosystems of the northern Tibetan Plateau. Environmental Earth Sciences 64: 1911-1919.

Li, L., Zhou, D.W. \& Sheng, L.X. 2012. Allometric relationship between mean component biomass and density during the course of self-thinning for Fagopyrum esculentum populations. Acta Ecologica Sinica 32: 3987-3997. [In Chinese.]

Lonsdale, W.M. 1990. The self-thinning rule: dead or alive? Ecology 71: 1373-1388.

Lonsdale, W.M. \& Watkinson, A.R. 1982. Light and self-thinning. New Phytologist 90: 431-445.

Mokany, K., Raison, R.J. \& Prokushkin, A.S. 2006. Critical analysis of root:shoot ratios in terrestrial biomes. Global Change Biology 12: 84-96.

Morris, E.C. 1999. Density-dependent mortality induced by low nutrient status of the substrate. Annals of Botany 84: 95-107.

Morris, E.C. 2002. Self-thinning lines differ with fertility level. Ecological Research 17: 17-28.

Morris, E.C. 2003. How does fertility of the substrate affect intraspecific competition? Evidence and synthesis from self-thinning. Ecological Research 18: 287-305.

Morris, E.C. \& Myerscough, P.J. 1991. Self-thinning and competition intensity over a gradient of nutrient availability. Journal of Ecology 9: 903-923.

Newman, E.I. 1973. Competition and diversity in herbaceous vegetation. Nature 44: 310-311.

Ogawa, K. 2005. Time-trajectory of mean phytomass and density during a course of self-thinning in a sugi (Cryptomeria japonica D. Don) plantation. Forest Ecology and Management 214: 104-110.

Osawa, A. \& Kurachi, N. 2004. Spatial leaf distribution and selfthinning exponent of Pinus banksiana and Populus tremuloides. Trees 18: 327-338.

Reynolds, J.H. \& Ford, E.D. 2005. Improving competition representation in theoretical models of self-thinning: a critical review. Journal of Ecology 93: 362-372. 
Thornley, J.H.M. 1972. A balanced quantitative model for root: shoot ratios in vegetative plants. Annals of Botany 36: 431441 .

Wu, J.S., Zhang, X.Z., Shen, Z.X., Shi, P.L., Yu, C.Q., Song, M.H. \& Li, X.J. 2012. Species richness and diversity of Alpine grasslands on the Northern Tibetan Plateau: effects of grazing exclusion and growing season precipitation. Journal of Resources and Ecology 3: 236-242.

Xue, L. \& Hagihara, A. 1999. Density effect, self-thinning and size distribution in Pinus densiflora Sieb. et Zucc. stands. Ecological Research 14: 49-58.
Yang, Y.H., Fang, J.Y., Ji, C.J. \& Han, W.X. 2009. Above- and belowground biomass allocation in Tibetan grasslands. Journal of Vegetation Science 20: 177-184.

Yoda, K., Kira, T., Ogawa, H. \& Hozumi, H. 1963. Self-thinning in overcrowded pure stands under cultivated and natural conditions. Journal of Biology of Osaka City University 14: 107-129.

Zhang, W.P., Xin, J., Bai, Y.Y. \& Wang, G.X. 2011. The difference between above- and below-ground self-thinning lines in forest communities. Ecological Research 26: 819-825. 